\title{
Flagellar apparatus transformation and development in Prorocentrum micans and $P$. minimum (Dinophyceae)
}

\author{
K. HemanN ${ }^{1 *}$, K.R. Roberts ${ }^{2}$ and R. Wetherbee $^{1}$ \\ ${ }^{1}$ School of Botany, University of Melbourne, Parkville 3052, Australia \\ ${ }^{2}$ Department of Biology, University of Southwestern Louisiana, Lafayette, LA 70504-2451, USA
}

\begin{abstract}
K. HeIMANN, K.R. RoBer TS AND R. WETHERBEE. 1995. Flagellar apparatus transformation and development in Prorocentrum micans and P. minimum (Dinophyceae). Phycologia 34: 323-335.

Flagellar transformation was studied in Prorocentrum minimum (Pavillard) Schiller on free-swimming cells using lowillumination light microscopy. Cells bear two ventrally inserted, heterodynamic flagella. Prior to cell division, two new transverse flagella are produced. The parental longitudinal flagellum (1) remains unaltered during cell division, while the parental transverse flagellum (2) is either retracted or abscissed, and regrows as a longitudinal fiagelium $\left(1_{2}\right)$. The basal apparatuses of both $P$. micans Ehrenberg and $P$. minimum show the typical complement of dinophycean roots at interphase. Two new daughter basal bodies $\left(2^{1}\right.$ and $\left.2^{2}\right)$ are formed prior to any alteration of the parental basal apparatus. The parental longitudinal microtubular root (LMR) and basal body connective (BBC) appear to be maintained unaltered and associated with the parental longitudinal basal body (1). A new longitudinal microtubular root ( $\mathrm{lmr}$ ), basal body connective (bbc) and fibrous connectives ( $\left.\mathrm{fc}^{\prime} \mathrm{s}\right)$ are produced between the transforming transverse basal body (2) and its daughter $\left(2^{2}\right)$. New striated root connectives (stc's), transverse striated roots (tsr's) and their associated microtubules (tsrm's) are formed next to the new, transverse daughter basal bodies $\left(2^{1}\right.$ and $2^{2}$ ). Basal body $2^{1}$ forms its own transverse microtubular root (tmr) while the same root on basal body $2^{2}$ might be derived from the parental transverse striated root microtubule (TSRM) as a result of root transformation and transfer. The parental transverse striated root (TSR) and transverse microtubular root (TMR) are disassembled during cell division. The pattern of flagellar root development is compared to other known root developmental processes for which we introduce a system of classification. We also introduce a flagellar root nomenclature similar to the flagellar nomenclature to indicate unaltered parental roots, newly formed roots, transferred roots and transformed parental roots that constitute another root type in the new daughter cell.
\end{abstract}

\section{INTRODUCTION}

Most algal flagellates bear two flagella differing in size, structure and function. Even in Chlamydomonas (Chlorophyta), whose flagella appear to be structurally identical, the flagella respond differently to various calcium concentrations (Kamiya \& Witman 1984) and show cell asymmetry in relation to the eyespot (Holmes \& Dutcher 1989). The semiconservative distribution of parental flagella and basal bodies during cell division was documented long ago (Doflein 1918; Cleveland 1963). Initial studies by Melkonian et al. (1987) on flagellar development in the prasinophyte Nephroselmis olivacea Stein led to the surprising conclusion that the two newly formed flagellar basal bodies are in the same developmental state, and that flagellar/basal body heterogeneity in a cell is based on the maturation (transformation) of one of the two parental flagella/basal bodies into the other type. Since its discovery in Nephroselmis, flagellar transformation has been observed in all the flagellate algae studied in detail (for a review see Beech et al. 1991). A similar developmental sequence can be deduced from published observations on the centrioles of mammalian $\mathrm{PtK}_{2}$ cells (Rieder \& Borisy 1982) and amoebae of the myxomycete Physarum polycephalum Schweinitz (Wright et al. 1985). It has thus been proposed that the extension of basal body/centriolar development over two or more cell cycles is a ubiquitous, intrinsic feature of all eukaryotic cells (Beech et al. 1988).

The transformation of a basal body is accompanied by the reorientation and reorganization of its associated roots, which in turn has major implications for cell symmetry. Much attention has been paid to flagellar transformation, as this process can be observed in vivo (Wetherbee et al. 1988; Heimann et al. 1989b; Beech \& Wetherbee 1990a). Studies of basal apparatus development and transformation (basal apparatus = basal bodies and attached flagellar roots) require detailed analyses of serial sections of numerous cells throughout the cell cycle, thus observations of this type have only been made on a few algal species (Beech \& Wetherbee 1988, 1990b; Brugerolle 1992; Perasso et al. 1992, Beech \& Melkonian 1993).

Here we report on flagellar development during cell division in a dinoflagellate. Cells of Prorocentrum micans Ehrenberg and $P$. minimum (Pavillard) Schiller, as well as most motile dinoflagellates, bear two distinctly heteromorphic and heterodynamic flagella: a longitudinal flagellum and a transverse flagellum. We describe the flagellar developmental cycle of $P$. minimum, using direct observations of living cells, and present a serial thin-section analysis of basal apparatus development and transformation throughout the cell cycle of $P$. micans and $P$. minimum.

\footnotetext{
* Address for correspondence.
} 


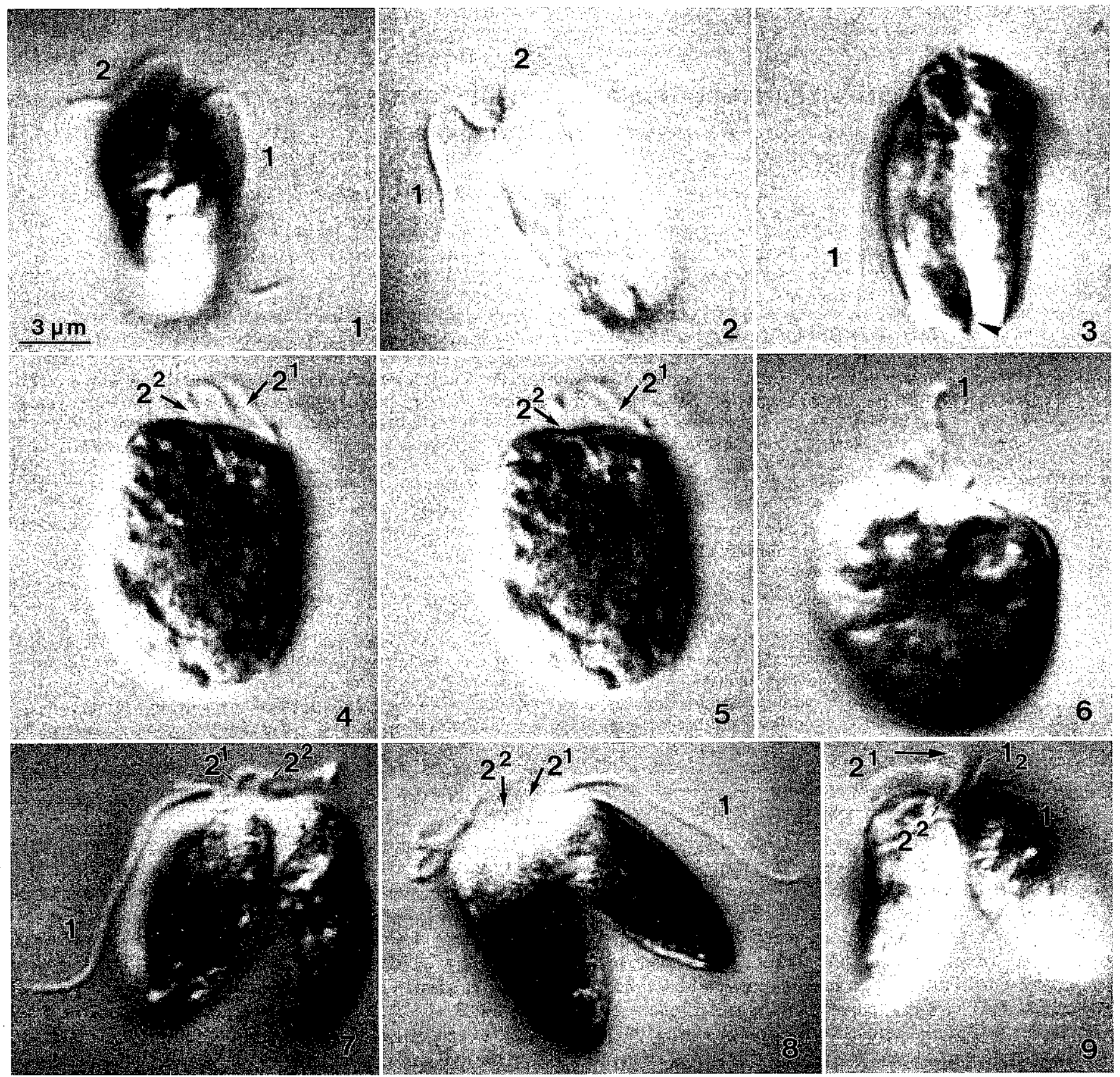

Figs 1-9. Light micrographs of a single, free-swimming cell of $P$. minimum during cell division.

Fig. 1. Orientation of F1 and F2 during interphase when viewed from the cell's right.

Fig. 2. The cell from the left side, having retracted its F2. Only a stump of F2 is visible,

Fig. 3. The same orientation after complete retraction of the F2. The AH is visible, the cell has broadened and the future cleavage furrow can already be predicted (arrowhead).

Figs 4-6. Side view of the same cell with the outgrowing $\mathrm{F} 2^{2}$ and $\mathrm{F} 2{ }^{1}$. The flagella originate in close proximity to one another and beat in synchrony. In Fig. 6 the cell has moved slightly, allowing an oblique view from the anterior side onto its ventral region. At this stage the cell appears to be triflagellate. The parental longitudinal Fl is indicated.

Figs 7-9. The cell just prior to division. Fig. 7 shows the left side and in Figs 8 and 9 the cell is viewed from the right side. Cell cleavage has progressed from the cell's posterior along the suture between the two valves, but the cell remains uncleaved in its apical part. In Figs 7--8 the cell appears to be triflagellate, but as it turns to allow a more apical view, both the transformed $F 1_{2}$, and the new longitudinal $F 1$ of the future left cell come into sight. The $\mathrm{Fl}_{2}$ is still short and will not continue to grow until cell division is completed.

NOTE: Nomenclature used in figures and legends: 1, longitudinal, (mature) basal body/flagellum (BB/F); 2, transverse (transforming) BB/F; $2^{1}$, new $\mathrm{BB} / \mathrm{F}$ associating with $\mathrm{BB} / \mathrm{F} 1 ; 2^{2}$, new $\mathrm{BB} / \mathrm{F}$ associating with $\mathrm{BB} / \mathrm{F} 2 ; 1$, transformed $\mathrm{BB} / \mathrm{F}$ prior to cytokinesis; $\mathrm{Al}$, apical horn; $\mathrm{BCC}$, parental basal body connector; the newly formed roots are abbreviated with lower-ease letters; $\mathrm{F}$, flagellum; $\mathrm{FC}$, fibrous connective; LMR, parental longitudinal microtubular root; P, peduncle; SRC, parental striated root connective; TMR, parental transverse microtubular root; TMRE, transverse microtubular root extension; TSR, parental transverse striated root; TSRM, parental transverse striated root microtubule; $2^{2} \mathrm{tmr}^{2}$ TSRM, parental transverse striated root microtubule being transformed into the transverse microtubular root of daughter basal body 


\section{MATERIALS AND METHODS}

Prorocentrum minimum Ehrenberg (Corio Bay, Australia, collected in March 1992 by Dr D.R.A. Hill) was grown in a modified K medium (Keller et al. 1987), which contained only half the amount of nutrients. It was maintained in a $14: 10 \mathrm{~h}$ $\mathrm{L}: \mathrm{D}$ cycle at $15^{\circ} \mathrm{C}$ in batch culture, illuminated with a photon fluence rate of $40 \mu \mathrm{mol} \mathrm{m} \mathrm{m}^{-2} \mathrm{~s}^{-1}$ and diluted every fifth day $1: 1$ with fresh culture medium. The growth rate was $c .0 .5$ divisions per day and samples for observation and fixation were taken $2 \mathrm{~h}$ before the onset of the light cycle.

For analysis of cell division and flagellar development in live cells, a drop of cell culture was placed in a slide chamber, covered with a coverslip and sealed with wax. Cells were observed using Nomarski differential interference contrast optics $[100 \times$ oil immersion objective, numerical aperture 1.25, Zeiss Photomicroscope III], coupled to an Interactive Video System, which allowed recording in real time on video. Agfa Pan film was used for photographic documentation.

For transmission electron microscopy, cells were initially fixed for $15 \mathrm{~min}$ in an equal volume of $0.1 \mathrm{M}$ sodium cacodylate containing $0.4 \mathrm{M}$ sucrose ( $\mathrm{pH} 7.0$ ), $4 \%$ glutaraldehyde and $2 \% \mathrm{OsO}_{4}$ at $4{ }^{\circ} \mathrm{C}$. Cells were then washed twice in $0.05 \mathrm{M}$ sodium cacodylate containing $0.2 \mathrm{M}$ sucrose. The sucrose content was then gradually reduced by the dropwise addition of $0.05 \mathrm{M}$ sodium cacodylate. Ceils were washed twice, followed by post-fixation in $1 \% \mathrm{OsO}_{4}$ in buffer at room temperature for $1 \mathrm{~h}$, rinsed three times in buffer, dehydrated in acetone and embedded in Spurr's resin (Spurr 1969). Serial thin sections were cut with a diamond knife in a Reichert Ultra- cut E ultramicrotome and viewed on Siemens 102 or Jeol 1200 transmission electron microscopes. $P$. micans was grown and fixed as stated in Roberts et al. (1995).

\section{RESUCTS}

\section{Nomenclature of flagella/basal bodies}

In interphase cells, the mature flagellum/basal body (here the longitudinal flagellum/basal body) is termed 1 , while the immature flagellum/basal body (here the transverse flagellum) is termed 2. Numbering and nomenclature of flagella is according to Heimann et al. (1989a) and Moestrup \& Hori (1989). During flagellar duplication, the newly formed flagellum/basal body that associates with the mature parental flagellum/basal body is designated $2^{1}$, while the newly formed flagellum/basal body that pairs with the transforming parental flagellum/basal body is termed $2^{2}$. Prior to cell division when the transforming basal body has completed the transformation process, it is termed $1_{2}$.

\section{Nomenclature of flagellar roots}

At interphase the parental roots are abbreviated by capital letters. Those parental roots that are maintained unaltered during cell division, either in the same position or transferred to another basal body, are indicated in division stages by capital letters, while a superscript number indicates the basal body that the root transferred from, e.g. ${ }^{2}$ TSRM. Roots that are newly formed during this cell division cycle are designated

$\overleftarrow{2^{2}}$, as indicated by the first set of numbers. It is transferred from the parental basal body 2 as indicated by the superscript number between tmr and TSRM. Although some structures have been labelled only once or twice, the same particular arrows are used throughout to indicate the same structures.

Figs 10a-d. Diagrammatic reconstruction of the basal apparatus at different developmental stages. The arrows at the TMRE, tmre, LMR and $\mathrm{Imr}$ indicate the course of these roots in the cell.

Fig. 10a. Basal apparatus at interphase.

Fig. 10b. Basal apparatus of an early division stage. The constituents of the parental basal apparatus (BBC, SRC, TSR, TSRM, TMR and TMRE) still connect parental basal bodies 1 and 2 while the daughter basal bodies $2^{1}$ and $2^{2}$ have formed. Basal body pair $2^{2}$ and 2 is connected by a newly formed bbc and a new lme has been produced, whereas basal body pair 1 and $2^{1}$ do not show an apparent connection. The parental TSRM by-passes basal body $2^{2}$ on the site where its tmr will originate. As this is different to the interphase condition, it suggests that the transformation of the parental TSRM into a tmr $\left(2^{2} \operatorname{tmr} r^{2}\right.$ TSR $)$ which is subsequently transferred from the parental basal body 2 to its daughter $2^{2}$. The tsrm, tsr of basal bodies $2^{1}$ and $2^{2}$ have formed. The two curved arrows indicate the clockwise rotation of the daughter basal bodies $2^{1}$ and the rotation of basal body pair 2 and $2^{2}$ which occurs prior to basal body pair segregation.

Fig. 10c. A later developmental stage just prior to basal body pair segregation. The direction of the latier is indicated by straight arrows. The parental TSR and TSRM are still present at this stage but no longer connected to the transformed basal body 12 .

Fig. 10d. Basal apparatus configuration just prior to cell division. The parental roots of the transformed parental basal body $1_{2}$ are at this stage completely disassembled. Both basal body pairs bear their entire set of roots and basal body/basal body pair rotation as well as segregation is complete.

Figs 11-18. Consecutive longitudinal serial sections of Prorocentrum micans. The view is from ventral, section progression is from dorsal. Views are on the proximal ends of the basal bodies where the parental longitudinal root (LMR) bends sharply towards the basal bodies. Mitotic prophase.

Fig. 11-12. The LMR (its bending part is indicated by the longer arrow), the basal body connective (indicated by white arrows), the SRC, the TSR and the FC can be identified and their connection to parental basal body 2 is visible in Fig. 12.

Figs 13-14. The TSRM progresses towards the daughter basal body $2^{2}$ (indicated by arrowhead). The newly formed lmr and daughter basal body $2^{1}$ are visible.

Figs $15-18$. The two parental basal bodies $(1$ and 2$)$ and their daughters $\left(2^{1}\right.$ and $\left.2^{2}\right)$ are shown. Fibrous components (fe, bbe) connect basal body $2^{2}$ to its parent (2), whereas basal body $2^{1}$ is connected to its parent (1) by the parental BBC which is still attached to the parental basal body 2 via a fibrous connective (FC). The newly formed tsr, tsrm (long arrow Fig. 17) of basal body $2^{2}$ and tsrm, tsr (arrowhead Fig. 16) of basal body $2^{1}$ are visible as well as the parental TRM of basal body 2 . 

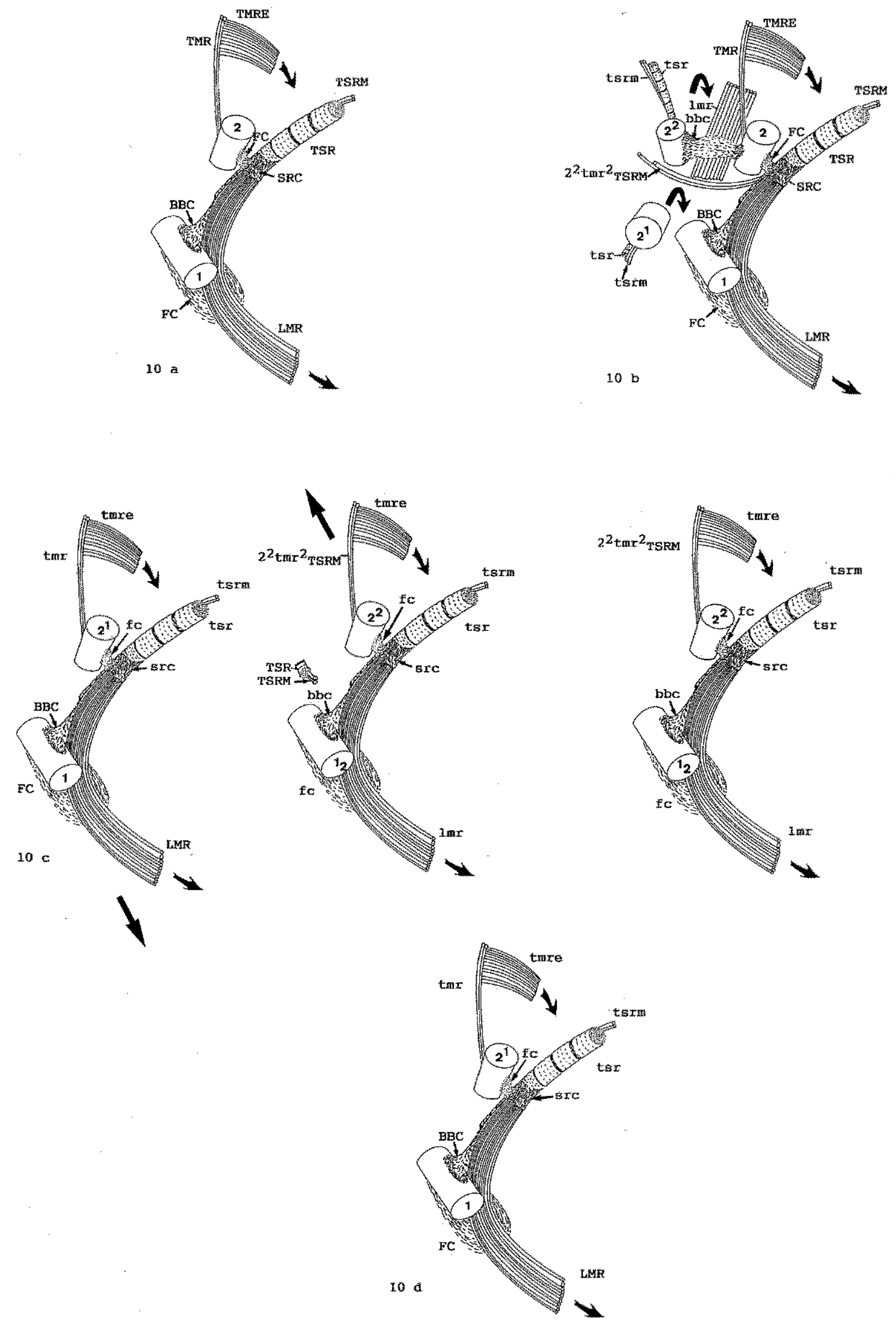

(C) 1995 International Phycological Society, Phycologia, 34, 323-335 


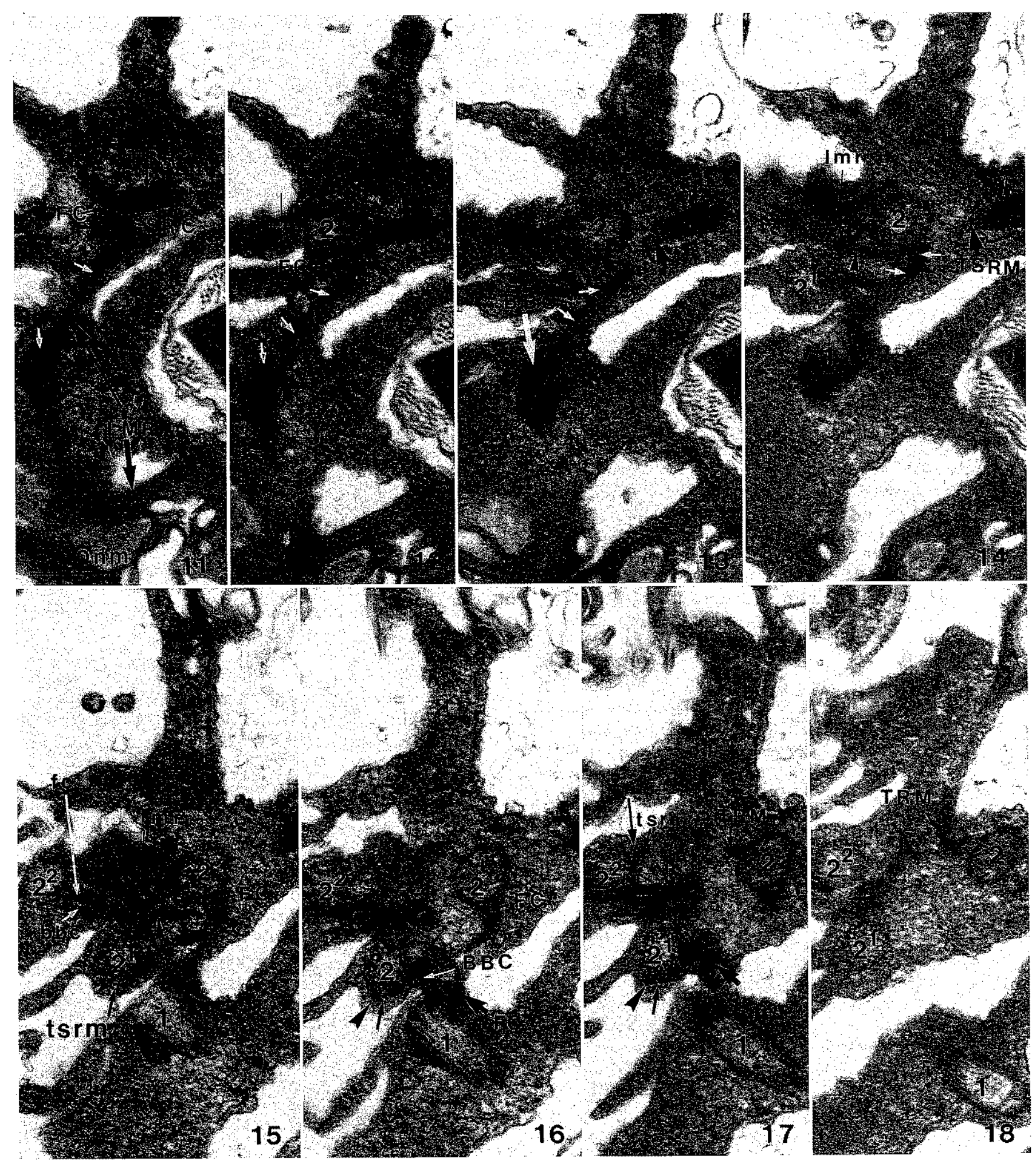


by lower-case letters. Those roots that transform from one type to another receive lower case letters and the former parental root abbreviation as a capital subscript to demonstrate clearly which parental root has been transformed into which new root (e.g. $\mathrm{tmr}_{\text {YSRM }}$ ). The number in front of the whole term indicates the basal body that receives the root, (e.g. $2^{2} \mathrm{tmr}_{\mathrm{TSR}}$ ). The abbreviation $2^{2} \mathrm{tmr}^{2}{ }_{\text {TSRM }}$ symbolizes that the parental transverse striated root microtubule was transformed into a transverse microtubular root and that this transformed root was transferred from the parental basal body 2 to its daughter $2^{2}$.

\section{Tlagellar development}

Flagellar transformation was studied in vivo by following a single cell throughout this process (Figs 1 -.9.). In the Prorocentrales the longitudinal and transverse flagella insert ventrally (Roberts et al. 1995) which was formerly referred to as an apical flagellation (for a review see Goldstein 1992). The transverse and longitudinal flagella can be distinguished due to their different beat patterns and their insertion (for a review see Goldstein 1992). The transverse flagellum (2) is coiled and lies roughly perpendicular to the longitudinal flagellum (1) which extends dorsally ('backwards') (Fig. 1). Flagellar development during cell division starts with the retraction of the parental transverse flagellum (2) (Figs 1-3) while the cell doubles its diameter (Fig. 3). The parental longitudinal flagellum (1) temains unaltered throughout cell division (Figs $1-3$, 6-8). Two new transverse fagella $\left(2^{1}\right.$ and $\left.2^{2}\right)$ are formed on the right side of the parental longitudinal flagellum and beat synchronously, making it difficult to view and distingursh between them (Figs 4-6, the viewer's left). Just prior to cell division, a new longitudinal flagellum $\left(l_{2}\right)$ is formed and is recognizably shorter than the parental longitudinal flagellum (1), a difference that is maintained until cell division is completed (Figs 7-9). At this stage in the cell cycle the new transverse flagella $\left(2^{1}\right.$ and $\left.2^{2}\right)$ have reached their final length. Cell division progresses from the cell's dorsal side along its right and left longitudinal axes between the anterior and posterior surface (Figs 3,7m, nomenclature of cell symmetry after Roberts et al, 1995). The period required for flagellar development until division is completed was $36 \mathrm{~h}$.

\section{Basal apparatus development}

Basal apparatus development first becomes apparent with the formation of two daughter basal bodies $\left(2^{1}\right.$ and $\left.2^{2}\right)$ to the right of each parental basal body (compare Fig. 10a (interphase) to Fig. $10 \mathrm{~b}$ (early division stage)). At this stage in the cell cycle the parental transverse basal body (2) and longitudinal basal body (1) show their interphase set of roots and fbrous connectives. (Figs 10a, b; Roberts et al. 1995), which are abbreviated by capital letters (Figs 10b, 11-22). While the parental basal apparatus is maintained, a new set of roots and connectives is formed between basal body 2 and its daughter $2^{2}$, consisting of a basal body connective (bbc) (Figs $10 \mathrm{~b}, 15,20-22$ ), a longitudinal microtubular root (mr) (Figs $10 \mathrm{~b}, 13-16,19-22$ ), the necessary fibrous connectives (fc's) (Figs 15, 16) and the striated root connective (sre) (Fig. 10b). A new transverse striated root (tsr) is formed at the anterior side of daughter basal body $2^{2}$ (Figs 10b, 17, 20-21) which is accompanied by transverse striated root microtubules (tsrm).
In order to maintain the absolute configuration of the basal apparatus, the basal body pair $2^{2}$ and 2 has to rotate approximately $90^{\circ}$ clockwise (Fig. $10 \mathrm{~b}$, indicated by a bent arrow). In contrast to daughter basal body $2^{2}$, basal body $2^{1}$ organizes its transverse striated root (tsr) and the transverse striated root microtubule (tsrm) on its posterior side (Figs 10b, 15-17). At this stage in the cell cycle, basal body $2^{1}$ seems to have no connection to basal body 1 (Fig. 10b). This lack of connection might facilitate its clockwise rotation in order to obtain the correct position to basal body 1 , which is indicated in Fig. $10 \mathrm{~b}$ by a bent arrow. It seems that the parental basal body connective (BBC) connects to basal body $2^{1}$ (Figs 14-17) as well as to the parental basal bodies 1 and 2 (Figs 12-14) in a slightly later division stage. The parental transverse striated root microtubule (TSRM) runs between the daughter basal bodies $2^{1}$ and $2^{2}$ on the opposing side of the newly formed transverse striated root (tsr) and transverse striated root microtubules (tsrm) of basal body $2^{2}$ (Figs 10b, 20-22). This position, as well as the close proximity to the new basal body connective (bbc) of the basal body pair 2 and $2^{2}$, suggests that the TSRM could be transformed into the transverse microtubular root (tmr) of basal body $2^{2}$ (symbolized in the schematic drawing as $2^{2} \operatorname{tmr}^{2}$ rska; Fig. 10b).

Basal body segregation and the fate of the parental roots is illustrated by two series of serial sections through the basal apparatus of $P$. minimum (Figs 23 44). An early stage of basal body segregation is documented in Figs $23-36$, showing that the transforming parental basal body $\left(\mathrm{I}_{2}\right)$ still bears its parental roots, the transverse striated root (TSR) (Figs 23-29) and its accompanying microtubules (TSRM) (Figs 26, 27) as well as the transverse microtubular root (TMR) (Figs 28, 29), while it is clearly connected to the new longitudinal microtubular root ( $\mathrm{lmr}$ ) by a prominent striated root connective (src) (Figs 30-33). Daughter basal body $2^{2}$ shows a complete set of roots at this stage in the cell cycle. The transverse striated root (tsr) and the two accompanying microtubules (tsrm"s) are connected via the striated root connective (src) to the longitudinal microtubular root (mr) which is attached to basal body $2^{2}$ by a fibrous connective (fc) (Figs 31-35). The transverse microtubular root extensions (tmre) of the transw verse microtubular root can be seen in Figs 32 and 41 . This basal body pair lies in the anterior half of the dividing cell. The basal body pair comprising the parental longitudinal basal body (1) and its daughter $2^{1}$ seem to bear a less developed transverse striated root (tsr) at this stage in the cell cycle (Figs 23-28).

A later stage in basal apparatus development is shown in Figs 10c, 37-44. The parental transverse microtubular root (TMR) and transverse striated root (TSR) are still present, but are no longer connected to the transformed basal body $\left(1_{2}\right)$ (Figs 10c, 37-40). The course of the newly formed $1 \mathrm{mr}$ of basal body $1_{2}$ is outlined by the same arrow (Figs 37-44)x The development of the transverse striated root (tsr) on daughter basal body $2^{1}$ has at this stage caught up with the one on basal body $2^{2}$ (Fig. 40). Transverse microtubular root extensions of the transverse microtubular root $\left(2^{2} \mathrm{tmr}^{2}{ }_{\text {TSRM }}\right)$ of basal body $2^{2}$ is shown in Fig. 41. The end of basal apparams development and transformation is illustrated in Figs 10d, 45-52. Basal body segregation is complete, the parental roots (TSR and TMR) have disassembled and both basal body pairs bear their entire set of roots. The parental longitudinal 


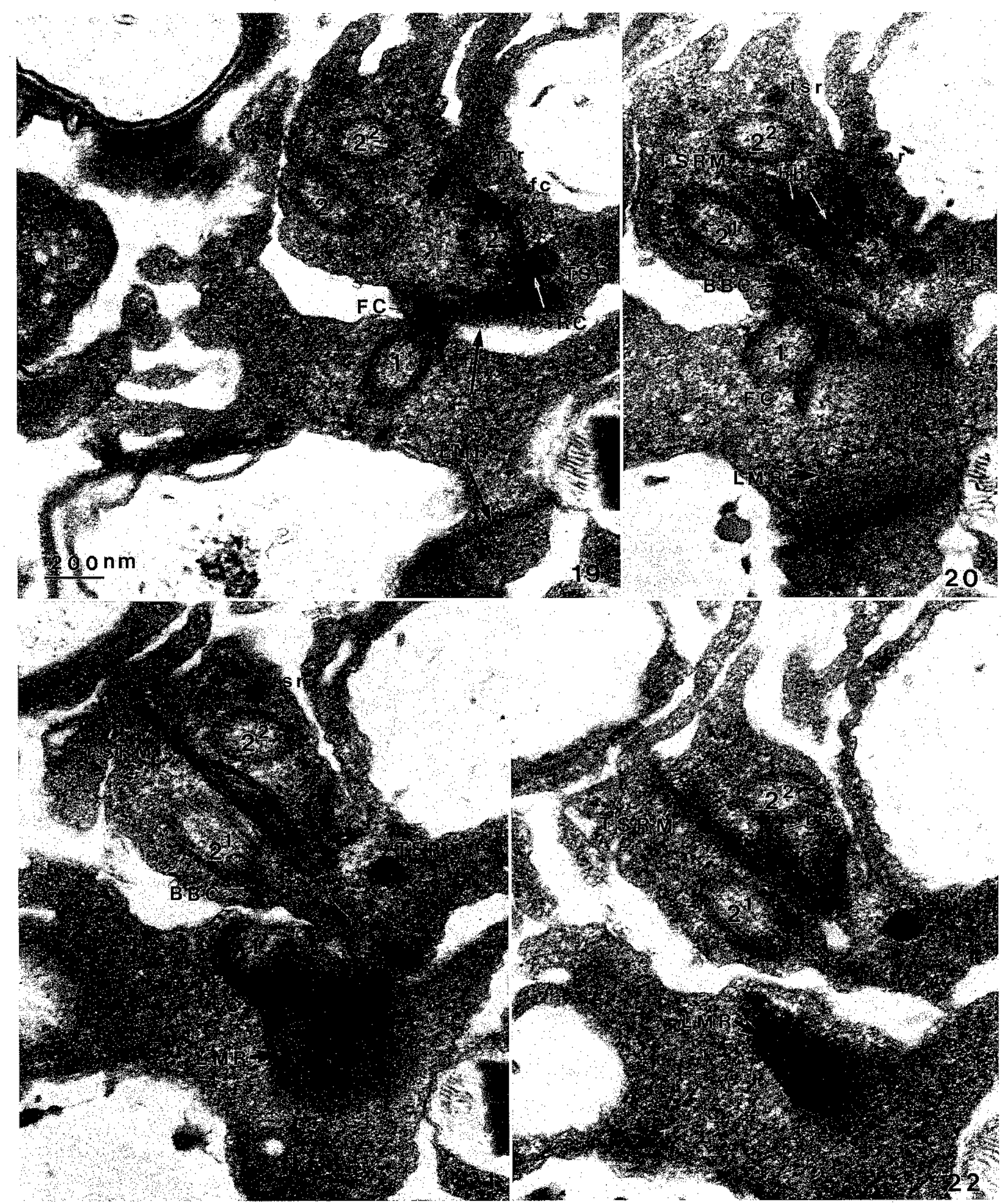

Figs 19-22. Consecutive serial sections of the basal apparatus of Prorocentrum micans viewed from the ventral side at prophase. Section progression is from dorsal. Note the course of the parental TSRM between the two daughter basal bodies $2^{2}$ and $2^{1}$ and its close proximity to the newly formed bbc. In addition to the features of the developing apparatuses introduced in the previous series (Figs 11-18) the parental SRC (visible in Fig. 11) and the fc can be identified connecting the parental basal body to the newly formed imr. 
microtubular root (LMR) is the only root that has been maintained without alteration. As both daughter basal bodies are formed towards the right of the parental basal bodies, cell symmetry is maintained for both daughter cells by either basal body $\left(2^{\frac{1}{3}}\right.$, Fig. 10b) or basal body pair (2 and $2^{2}$, Fig. 106) rotations and basal body pair migration (Fig. 10c). These events are indicated in Figs 10b, 10c by curved and straight arrows. The parental cell's posterior side is the posterior surface for one daughter cell while its anterior side constitutes the anterior side for the other daughter cell. Fibrous material of unknown function underlies the region of the basal body pair $I_{2}$ and $2^{2}$ (Figs 46-47).

\section{DISCUSSION}

The isolated systematic position of the Dinophyceae (Dodge 1983) has given rise to considerable speculation about its phylogeny and relationship to other algal groups (see comprehensive works by Spector 1984; Taylor 1987; Farmer \& Roberts 1989; Roberts \& Roberts 1991). The organization of the flagellar apparatus and the cytoskeleton has been used by Roberts (1991) to discuss the systematic affinities within the Dinophyceae. In addition, it has been assumed that morphologically similar flagellar roots in different algal taxa may be homologous structures (Sleigh 1988) that connect to basal bodies of the same developmental stage (Farmer \& Roberts 1989; Roberts \& Roberts 1991). However, when the flagellar roots of the transverse basal body in different dinofiagellates were compared to similar roots of other flagellates, conflicting conclusions resulted. Farmer \& Roberts (1989) described a transverse microtubular root/transverse microtubular root extension complex (TMR/TMRE complex) associated with the transverse basal body in Amphidinium that can be also identified in both Prorocentrum species. The authors compare

Figs 23-36. Non-adjacent serial sections of the developing basal apparatus of Prorocentrum minimum prior to basal body segregation. The view and the section progression are from ventral at an oblique transverse angle.

Fig. 23. Section showing the parental longitudinal basal body (1) and its daughter $2^{\mathrm{x}}$, the parental LMR and TSR, and the transforming basal body 1

Fig. 24. The FC connects basal body 1 to the parental LMR which is marked by a small arrow. The TSR is indicated by a medium sized arrow.

Fig. 25. Two fibrous connectives (FC) link basal body 1 to the LMR.

Fig. 26. The TSRM is shown and the accompanying the TSR marked by a medium-sized arrow. The FC of basal body 1 is indicated by a slender arrow.

Fig. 27. Note the peduncle (P) on the left side of the basal bodies. A newly formed fibrous connective (fc) connects basal body $2^{2}$ to the parental LMR (second arrow from the left). The TSRM of the transforming basal body $1_{2}$ is indicated by a medium-sized arrow and the TSR is visible.

Fig. 28. The newly formed tmr and tsrm are connected to basal body $2^{2}$. The connection of the parental TMR and TSR to basal body ${ }_{2}$ is also shown.

Fig. 29. Section shows the progression of the TMR marked by a medium-sized arrow.

Fig. 30. Note the newly formed lmr (arrow) connected to the transforming basal body $1_{2}$. Flagellum/basal body $2^{2}$ comes into sight. Note the pedunde $(P)$ on the left.

Fig. 31. A prominent newly formed src (arrowheads) shows connection to the lme (arrow).

Fig. 32. The newly formed trme of basal body $2^{2}$ bypasses the sre.

Fig. 33. The sre (arrowheads) is connected to the imr (arrows) and the tsr which is accompanied by the tsrm.

Fig. 34. Basal body $2^{2}$ is connected to the imr (bigger arrow) by a newly formed fibrous connective (fc). The tsrm and tsr are indicated by medium sized arrows. The $2^{2} \mathrm{tmr}^{2}{ }^{2}$ rew can be seen.

Fig. 35. Basal body $2^{2}$ is connected to the $\operatorname{lm}$ (large arrow) by the fc. The $2^{2}$ tmrt ${ }^{2}$ tsm is pointed out by the smaller arrow.

Fig. 36. The $2^{2}$ tmr $^{2}$ TSRM (small arrow) and the imr (large arrow) are close to basal body $2^{2}$.

Figs 37-44. Non-adjacent, oblique longitudinal serial sections of the developing basal apparatus of Prorocentrum minimum during basal body segregation. At this stage the parental roots TSR and TMR show no apparent connection to the transformed basal body $1_{2}$.

Fig, 37. The parental LMR is connected to basal body 1 via a fibrous connective (FC). Daughter basal body $2^{1}$ is also visible. The parental TSR and TMR can be seen as well as flagella $l_{2}$ and $2^{2}$.

Fig, 38. The $2^{2} \operatorname{tmr}^{2}{ }_{\text {TSRM }}$ can be identified at the flagellum/basal body $\left(1_{2}\right)$ transition. The TMR and TSR are indicated by small arrows and the Imar is marked on the right.

Fig. 39. The LMR (medium short arrow) is connected to basal body 1 by the parental fibrous connective (FC) and to basal body $2^{1}$ by a newly formed fibrous connective (fc). The $2^{2} \mathrm{tmr}^{2}$ TSRM of basal body $2^{2}$ is marked by a slender arrow. The TSR and TMR are indicated by short thin arrows and the lmr by a short thick arrow.

Fig. 40. The newly formed tsr and tsrm of basal body $2^{1}$ can be seen. The course of the $2^{2} \mathrm{tmr}^{2}{ }_{\mathrm{TSR}}$ (slim longer arrow) and the TSR (short thin arrow) are indicated.

Fig. 41. The tmre of basal body $2^{2}$ can be seen for the first time to abut from the $2^{2}$ tmot ${ }^{2}$ rsg and the $1 \mathrm{mr}$ (fat arrow) connects to the transformed basal body $1_{2}$.

Figs 42-43. The tsr is accompanied by the double stranded tsm and connects to the Imr (fat arrow) via the sre (short arrow).

Fig. 44. The daughter basal body $2^{2}$ connects to the lmr by a fibrous connective (fc).

Figs 45-52. Adjacent serial transverse sections of the segregated basal apparatuses of Prorocentrum minimum. The cell is viewed from the ventral side, sections progress from dorsal. Note fibrous material (asterisks) in the region of basal body pair $2^{2}$ and $1_{2}$. At this stage in the cell cycle the parental TSR and TMR that are not transformed or maintained have broken down. The tmr and tsr of both basal body pairs are newly formed. Only the parental LMR and $\mathrm{BBC}$ and one fibrous connective connecting basal body 1 to the LMR (not shown here) have been maintained unaltered. All other root components and fibrous connectives are newly formed, as indicated by lower-case letter abbreviations, with the exception of the $2^{2} \mathrm{tm} \mathrm{r}^{2}$ rsra of basal body $2^{z}$ which is the transformation product of the parental TSRM as indicated by the subscript index. 


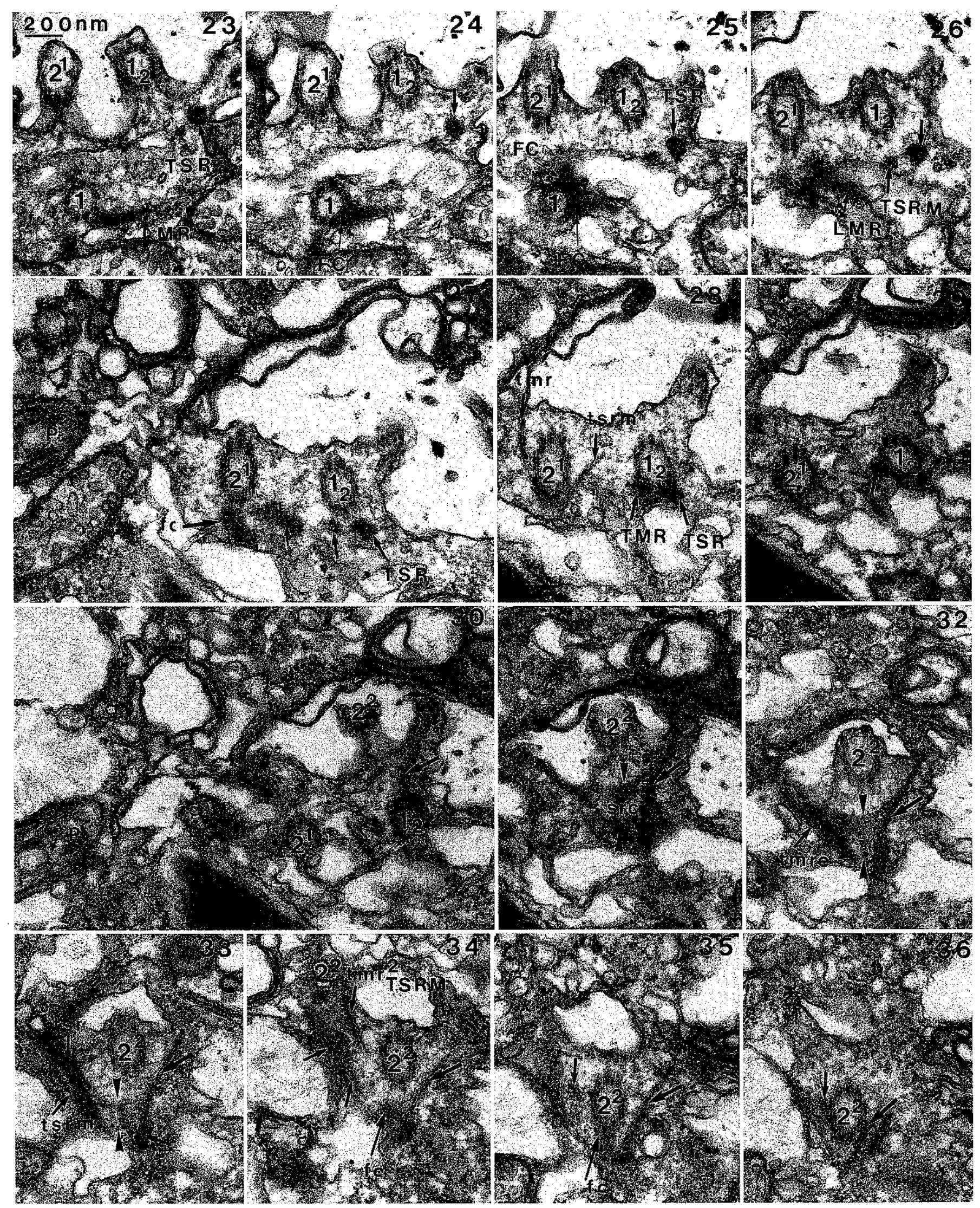




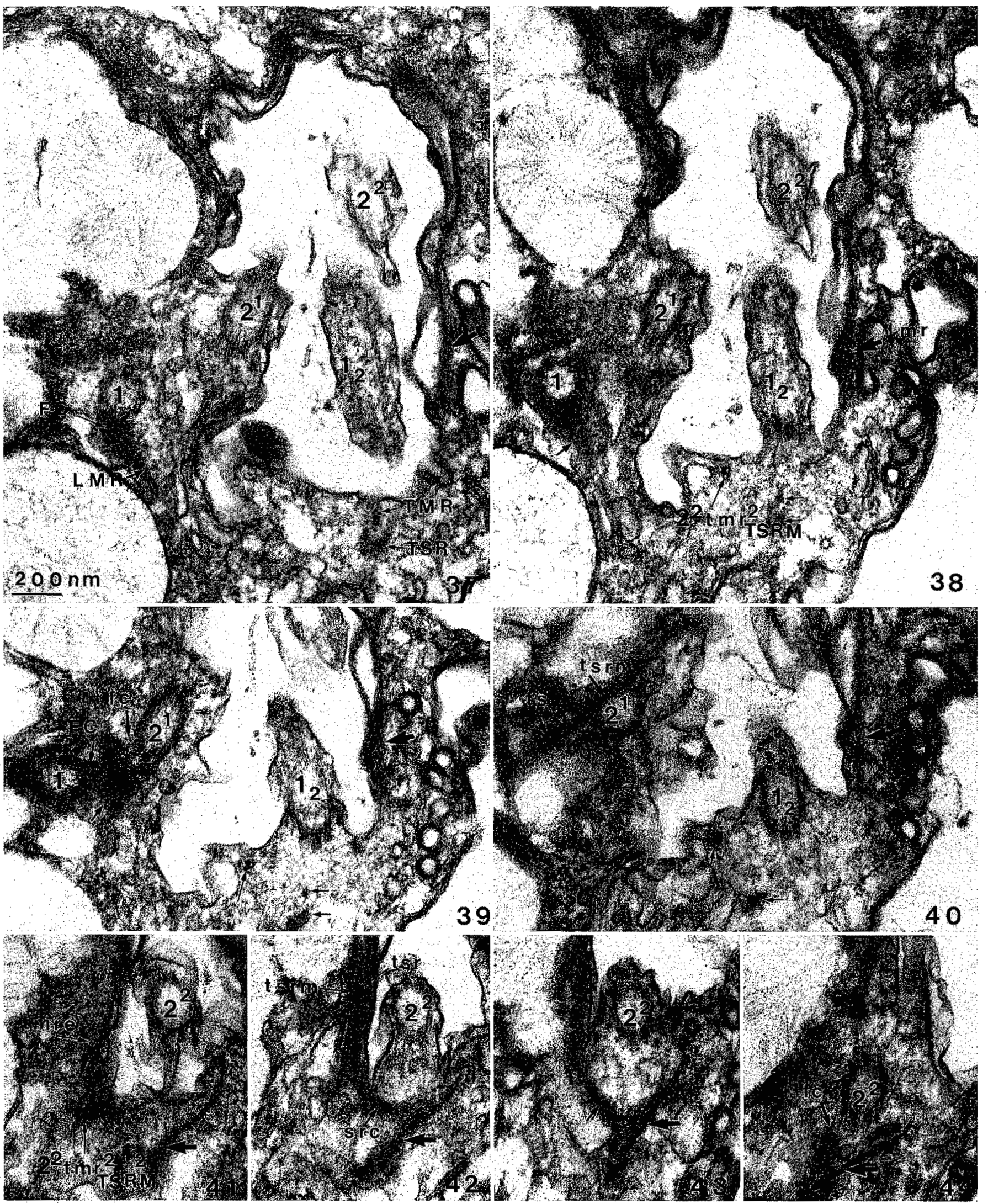




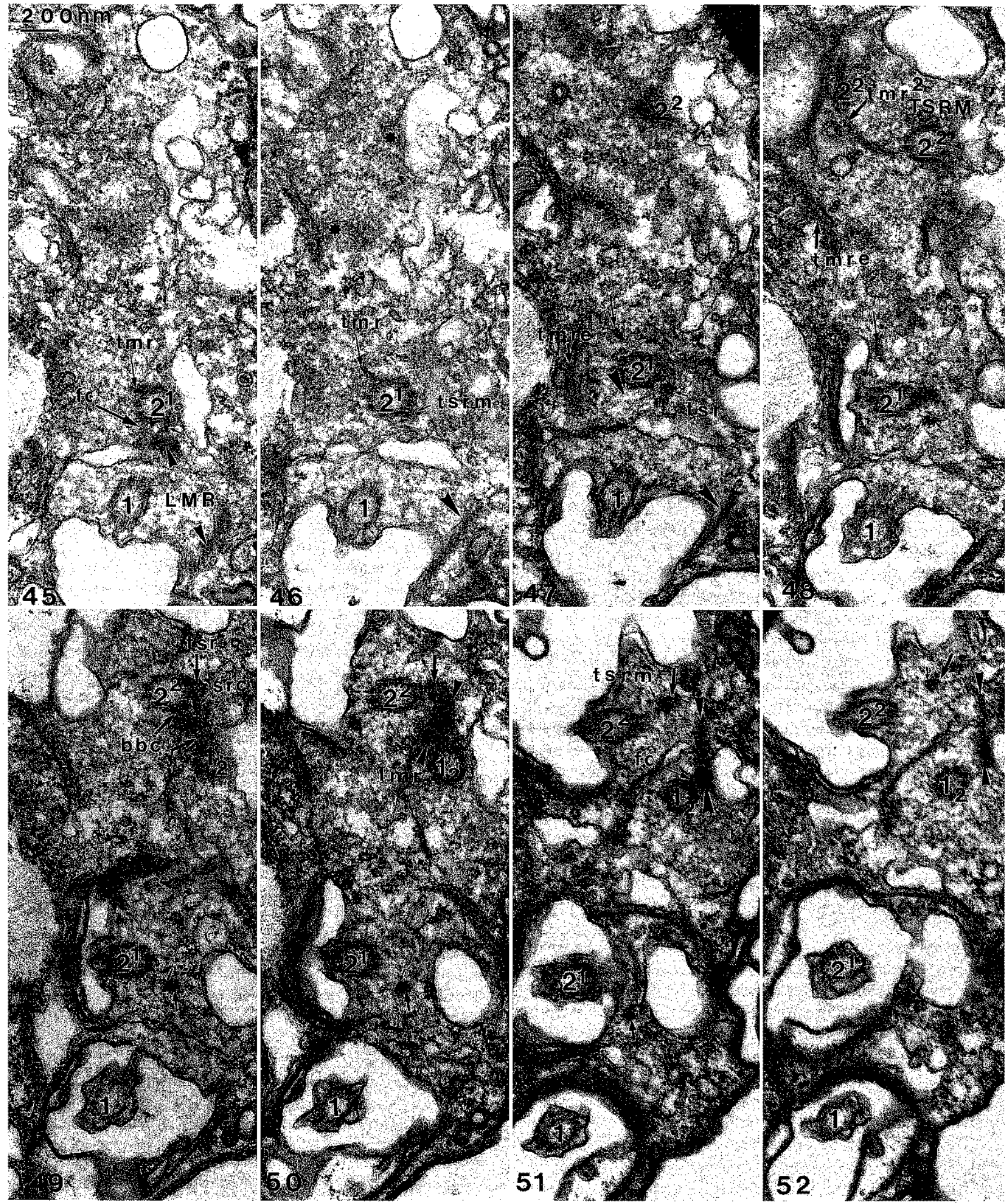


the complex with the cytoplasmic microtubules associated with the $\mathrm{R} I$ root of the mature basal body in the prymnesiophyte Pleurochrysis carterae Braarud et Fagerlund (Beech \& Wetherbee 1988; Beech et al. 1988) and imply that the state of maturation may be homologous in Amphidinium. The TMR/TMRE complex may also be compared to the R1 root of heterokonts where it connects to the immature basal body (Beech \& Wetherbee 1990b). A transverse striated root, which may or may not be accompanied by microtubules, has been described as associated with the transverse basal body in numerous dinoflagellates (Roberts 1991; Roberts \& Roberts 1991), and a similar root is associated with the immature basal body in Cryptomonas ovata Ehrenberg (Perasso et al. 1992). It is also worth noting that the flagellar apparatus of ciliates possesses a striated fibre (Peck 1977; Lynn 1988, 1991) thought to be connected to the mature basal body (Roberts \& Roberts 1991), but it extends to the cell's right, and not to the left as found in dinoffagellates (Roberts \& Roberts 1991; Roberts et al. 1992). Furthermore, Roberts et al. (1992) assume that this striated fibrous root does not contain centrin, a calcium modulated protein, as do striated roots of other algal groups (Melkonian 1989). Hence, based on the comparison of roots that are thought to be homologous in different flagellate taxa, no unequivocal conclusion can be drawn on the developmental stage of the transverse basal body in dinoffagellates.

In our analysis of flagellar transformation in Prortocentrum micans and $P$. minimum, the main features of basal apparatus development include the breakdown of roots of the transverse basal body 2 , the nucleation of new roots and the possible transformation of the parental transverse striated root microtubules (TSRM) into a transverse microtubular root ( $\operatorname{tmr}_{\text {TSRA }}$ ) that is then transferred to daughter basal body $2^{2}\left(2^{2} t \mathrm{tmr}^{2}\right.$ TSRM $)$. This latter root disassembles during the following cell cycle and hence requires three developmental cycles to mature. Thus the immature, transverse basal body 2 is transformed into a longitudinal basal body $1_{2}$. Concurrent with the transformation process, the new transwerse basal bodies $2^{x}$ and $2^{2}$ are formed, synthesizing their own set of roots with the exception of the transverse microtubular root $\left(2^{2} \mathrm{tmr}^{2} \mathrm{TSR}\right)$ of basal body $2^{2}$. After root formation is complete, the basal body pairs are segregated to the future daughter cells while the parental roots (TSR and TMR) break down.

Flagellar root development has been described in the prymnesiophyte Pleurochrysis carterae (Beech ef al. 1988), in several chlorophytes (Aitchison \& Brown 1986; Gaffal 1988; Segaar \& Gerritsen 1989, Sluiman \& Blornmers 1990), the synurophyte Mallomonas splendens G.S. West (Beech \& Wetherbee 1990b), the cryptophyte Cryptomonas ovata (Perasso et al. 1992) and two euglenoids (Farmer \& Triemer 1988; Brugerolle 1992). Four different mechanisms of flagellar root development can be distinguished thus far.

I. Parental roots break down, or alternatively may be preserved in a reduced form [Pleurochrysis carterae (Prymnesiophyceae), Beech et al. 1988; Mallomonas splendens (Synurophyceae), Beech \& Wetherbee 1990b].

II. Parental roots are maintained or slightly reduced [Polytomella (Chloropliyta), Aitchison \& Brown 1986; Chlamydomonas (Chlorophyta), Gaffal 1988; Ploeotia costata Triemer (Euglenophyta), Farmer \& Triemer 1988; Brachiomonas
(Chlorophyta), Segaar \& Gerritsen 1989, and Chlorosarcina (Chlorophyta), Sluiman \& Blommers 1990].

III. Parental roots are transformed [Entosiphon sulcatum (Dujardin) Stein (Euglenophyta), Brugerolle 1992; Cryptom monas ovata Ehrenberg (Cryptophyta), Perasso et al. 1992].

IV. Parental roots are transferred [Cryptomonas ovata (Cryptophyceae), Perasso et al. 1992].

The mechanism of flagellar root transformation and development in Prorocentrum micans and $P$. minimum shows fea. tures of all four mechanisms. The parental longitudinal root (LMR), the fibrous connective (FC) that links basal body 1 to the LMR, and the basal body connective (BBC) between basal body 1 and its daughter $2^{\circ}$ are all naintained in an apparently unchanged form (mechanism II). The transforming basal body $1_{2}$ nucleates a new longitudinal microtubular root (mechanism $\mathrm{I}$ ) while its original roots are maintained and remain associated with it at this stage in the developmental cycle. Then, prior to the segregation of the basal body pairs, the transverse striated root (TSR), transverse mictotubular root (TMR) and various connectives (FC and $\mathrm{SRC}$ ) of the transforming basal body $1_{2}$ are disassembled (mechanism 1 ). The daughter basal bodies form their roots de novo with the exception of the transverse microtubular root $\left(2^{2} \mathrm{tmr}^{2}{ }_{\text {TSRM }}\right)$ of daughter basal body $2^{2}$. This root is a transformation product, as indicated by the subscript abbreviation, of the parental transverse striated root microtubule (TSRM) that is subsequently transferred from the parental basal body 2 , as shown by the superscript number 2 (mechanisms III and IV). Root transformation (Brugerolle 1992; Perasso et al. 1992), as well as root transfer processes (Perasso et al. 1992; $P$. micans and $P$. minimum, this study) are very recent discoveries, and their function may be to preserve cell symmetry/asymmetry during division.

It has been hypothesized that the segregation of basal bodies and flagellar roots among daughter cells during division may be partially effected by flagellar root mediated sliding (Segaar \& Gerritsen 1989; Sluiman \& Bloomers 1990), The possible participation of the basal apparatus in basal body segregation in Prorocentrum could not be ascertained in this study, though it is intriguing that basal apparatus components are synthesized prior to basal body segregation as in several other cases (e.g. Pyramimonas, Moestrup \& Hori 1989) and remain associated with their individual basal body pairs during migration. A further indication in support of basal apparatus participation in basal body pair orientation and maintenance of pairs during the segregation process is the fibrous connectives and striated root connectives that form and are maintained between the individual basal body pairs prior to basal body segregation. It is also of interest that flagellar root formation of basal body $2^{1}$ is slightly delayed when compared to that on basal body $2^{2}$, as the basal body pair $1_{2}$ and $2^{2}$ has to travel a longer distance to reach their destination.

\section{ACKNOWLEDGEMENT}

KH wishes to thank the Deutsche Forschungsgemeinschaft for a postdoctoral fellowship (He 1978/1-1). KRR wishes to thank the National Science Foundation for stpport of this study through grant \#BSR 91 07043. Funding was provided 
by the Australian Research Council (RW). The authors thank Drs D.R.A. Hill and P.L. Beech for helpful discussions.

\section{REFERENCES}

AITCHISON W.A. \& BRown D.L. 1986. Duplication of the flagellar apparatus and cytoskeletal microtubule system in the alga Polytomella. Cell Motility and the Cytoskeleton 6: 122-127.

BeEch P.L., Heimann K. \& Melkonian M. 1991, Development of the flagellar apparatus during the cell cycle in unicellular algae. Protoplasma 164: 23 37.

BEECH P.L. \& MELKONIAN M. 1993. The basal apparatus of the quadriflagellate Spermatozopsis exsultans (Chlorophyceae): numbering of basal body triplets reveals triplet individuality and developmental modifications. Journal of Phycology 29: 191-202.

BeECh P.L. \& Wetherber R. 1988. Observations on the flagellar apparatus and peripheral endoplasmic reticulum of the coccolithophorid Pleurochrysis carterae (Prymnesiophyceae). Phycologia 27. 142-158.

Beech P.L. \& Wetherbee R. 1990a. Direct observations on flagellar transformation in Mallomonas splendens (Synurophyceae). Journal of Phycology 26: 90 95 .

BEECH P.L. \& WETHERBEe R. 1990b. The flagellar apparatus of Mallomonas splendens (Synurophyceae) at interphase and its development during the cell cycle. Journal of Phycology 26: 95--111.

BeeCh P.L., Wetherbee R. \& Pickett-Hiaps J.D. 1988. Transformation of the flagella and associated flagellar components during the cell division in the coccolithophorid Pleurochrysis carterae. Protoplasma 145: $37-46$.

BRUGEROLLE G. 1992. Flagellar apparatus duplication and partition, flagellar transformation during division in Entosiphon sulcatum. BioSystems 28: 203-209.

Cleveland L.R, 1963. Function of flagellate and other centrioles in cell reproduction. In: The Cell in Mitosis (Ed. by L. Levine), pp. 3-53. Academic Press, New York.

Doflein F. 1918. Beiträge zur Kenntnis von Bau und Teilung der Protozoenkerne. Zoologischer Anzeiger 46: 289-306.

DODGE J.D. 1983. Dinofiagellates: investigation and phylogenetic speculation. British Phycological Journal 18: 335-356.

FARMER M.A. \& RoBERTS K.R. 1989. Comparative analysis of the dinoflagellate flagellar apparatus. III. Freeze substitution of Amphidinium rhynchocephalum. Joumal of Phycology 25: 280-292.

FARMER M.A. \& TrIEMER R.E. 1988. Flagellar systems in the euglenoid flagellates. BioSystems 21: 283 -291.

GAFFAL K.P. 1988. The basal body-root complex of Chlamydomonas reinhardtii during mitosis. Protoplasma 143: 118-129.

GoLdstein S.F. 1992. Flagellar beat patterns in algae. In: Algal Cell Motility (Ed. by M. Meikonian), pp. 99-153. Chapman and Hall, New York, London.

Heimann K., Reiza I.B. \& Melkonian M. 1989a. The flagellar developmental cycle in algae: flagellar transformation in Cyanophora paradoxa (Glaucocystophyceae). Protoplasma 148: 106-110.

Heimann K., Benting J., Timmermann S. \& Melkonian M. $1989 \mathrm{~b}$. The fiagellar developmental cycle in algae: two types of flagellar development in uniflagellated algae. Protoplasma 153: 14-23.

HOLmes J,A. \& DUtCHER S.K. 1989. Cellular asymmetry in Chlamy. domonas reinharditi. Journal of Cell Science 94: 273-285.

Kamrya R. \& Wrtman G.B. 1984. Submicromolar levels of calcium control the balance of beating between the two flagella in demembranated models of Chlamydomonas. Joumal of Cell Biology 98: 97-107.

Keller D.K., Selyin R.C., Claus W. \& Gunllard R.R.L. 1987. Media for the culture of oceanic ultraplankton. Journal of Phycol ogy 23: $633-638$.
LYNN D.H. 1988. Cytoterminology of cortical components of ciliates: somatic and oral kinetids. BioSystems 21: 299-307.

LYNN D.H. 1991. The implications of recent descriptions of kinetid structure to the systematics of ciliated protists. Protoplasma 164: $123-142$.

MelKoniAn M. 1989. Centrin-mediated motility: a novel cell motility mechanism in eukaryotic cells. Botanica Acta 102: 3-4.

Melkonian M., Reize I.B. \& PReisig H.R. 1987. Maturation of a flagellum/basal body requires more than one cell cycle in algal flagellates: studies on Nephroselmis olivacea (Prasinophyceae). In: Algal Development. Molecular and Cellular Aspects (Ed. by W. Wiessner, D.G. Robinson \& R.C. Starr), pp. 102-13. Springer Verlag, Berlin, Heidelberg, New York, Tokyo.

MOESTRUP $\varnothing$. \& HORI T. 1989. Ultrastructure of the flagellar apparatus in Pyramimonas octopus (Prasinophyceae) II. Flagellar roots, connecting fibres, and numbering of individual fiagella in green algae. Protoplasma 148: 41-56.

PECK R.K. 1977. Cortical ultrastructure of the scuticociliates Dexiotricha media and Dexiotricha copidiopsis (Hymenostomata). Journal of Protozoology 24:122-34.

Perasso L., Hill D.R.A. \& Wetherbee R. 1992. Transformation and development of the flagellar apparatus of Cryptomonas ovata (Cryptophyta) during cell division. Protoplasma 170: 53-67.

RIEDER G.L. \& Borisy G.G. 1982. The centrosome cycle in PtK cells: asymmetric distribution and structural changes in the pericentriolar material. Biology of the Cell 44: 117-32.

ROBERTS K.R. 1991. The flagellar apparatus and cytoskeleton of dinoflagellates: organization and use in systematics. In: The Biology of Free-living Heterotrophic Flagellates (Ed. by D.J. Patterson \& J. Larsen), pp. 285-302. Systematic Association Special Volume 45. Clarendon Press, Oxford.

Roberts K.R., Hemann K. \& Wetherbee, R. 1995. The flagellar apparatus and canal structure in Prorocentrum micans (Dinophyceae). Phycologia 34: 313-322.

RoBerTs K.R., RoBfris J.E. \& CORMIER S.A. 1992. The dinoflagellate cytoskeleton. In: The Cytoskeleton of the Algae (Ed. by D. Menzel), pp. 19-38. CRC Press, Boca Raton, Ann Arbor, London, Tokyo.

RoBErTS K.R. \& RoBerts J.E. 1991. The flagellar apparatus and cytoskeleton of the dinoflagellates. A comparative overview. Protoplasma 164: 105-122.

SegaAr P.J. \& GerRitsen A.F. 1989. Flagellar roots as vital instruments in cellular morphogenesis during multiple fission (sporulation) in the unicellular green flagellate Brachiomonas submarina (Chlamydomonadales, Chlorophyta). Cryptogamic Botany 1: 249-224.

SLeigh M.A. 1988. Flagellar root maps allow speculative comparisons of root patterns and their ontogeny. Biosystems 21: 277-282.

SLUIMAN H.J. \& BLommers P.C.J. 1990. Basal apparatus behaviour during cellular division (sporulation) in the coccoid green alga Chlorosarcina. Protoplasma 155: 66-75.

SpeCtor D.L. 1984. Dinoflagellates. Academic Press, Orlando. $545 \mathrm{pp}$.

SPURR A.R. 1969. A low-viscosity epoxy resin embedding medium for electron microscopy. Journal of Ultrastructural Research 26: $31-43$.

TAYLOR F.J.R. 1987. The biology of dinoflagellates. (Botanical Monographs, Vol. 21.) Blackwell, Oxford. $785 \mathrm{pp}$.

Wetherbee R., Platt S.J., Beech P.L. \& Pickett-Heaps J.D. 1988. Flagellar transformation in the heterokont Epipyxis pulchra (Chrysophyceae): direct observations using image enhanced light microscopy. Protoplasma 145: 47-54.

Wright M., Mrr L. \& Morsand A. 1985. Spatial relationships between the anterior centriole and mitotic centre during interphase in the amoebae of the myxomycete Physarum polycephalum. Developmental Genetics 5: 227-238.

Accepted 23 January 1995 